\title{
Control de calidad en radioterapia externa conformada e IMRT
}

J. Roselló

\section{Introducción}

Un sistema de control de calidad será un conjunto de acciones necesarias para asegurar que un producto se adecúa a unos determinados estándares de calidad. Por tanto, un programa de control de calidad requiere la existencia de los siguientes elementos:

- Que exista un estándar de referencia bien definido en términos objetivables.

- Medida, en nuestro producto, de aquellas propiedades que definen el estándar.

- La comparación del resultado obtenido de estas medidas con el estándar, lo cual nos va a requerir el establecimiento de criterios de aceptabilidad compatibles con las incertidumbres de estas medidas.

- Establecer unos criterios de actuación en el caso de que no se cumplan estos criterios de aceptabilidad.

La cadena de procedimientos involucrados en la radioterapia, a los cuales tendremos que aplicar criterios de control de calidad es la siguiente:

1. Evaluación clínica.

2. Decisión terapéutica.

3. Obtención de imágenes 3D.

4. Localización del volumen blanco y de los órganos de riesgo.

5. Planificación del tratamiento:

a) Simulación y cálculo de dosis.

b) Evaluación y selección.

6. Verificación dosimétrica y chequeos.

7. Posicionamiento del paciente.

8. Tratamiento.

9. Evaluación e investigación posterior.

Vamos a centrarnos en los aspectos de control del planificador, acelerador y verificación experimental de los tratamientos, puesto que los temas de inmovilización y control del posicionamiento ya se tratan en otras ponencias:

\section{Control del planificador}

Comprenderán fundamentalmente:

- Factores geométricos (fidelidad geométrica respecto a la máquina emisora de radiación). Se realizarán en el comisionado del planificador y posteriormente en cada una de las actualizaciones del software.

- Aspectos dosimétricos básicos (dosis absoluta, distribuciones de dosis, etc).

- Aspectos dosimétricos especiales (OF de campos pequeños, transmisión de las láminas y penumbras).

\section{Algoritmos de optimización}

Mientras que en los tratamientos convencionales utilizamos campos grandes, en los tratamientos de IMRT utilizamos campos que pueden involucrar segmentos de muy pequeño tamaño. La fidelidad del cálculo de estos por parte del sistema de planificación nos va a obligar a establecer unos límites, tanto en el tamaño mínimo de estos como en la fluencia de cada uno de ellos.

Por otra parte, habrá que chequear el modelado de la transmisión de las láminas en nuestro planificador. Además, el valor de la transmisión nos va a limitar la fluencia total con segmentos y por tanto el número de unidades de monitor de todo el tratamiento. Una trasmisión de las láminas elevada va a contribuir a una dosis integral alta en el paciente, cosa no deseable.

\section{Chequeos del acelerador}

- Colimador multiláminas: campos colindantes, reproducibilidad y exactitud en el posicionamiento de las láminas.

- Verificación del centro de rotación de los tres ejes.

- Reproducibilidad de los tratamientos a lo largo del tiempo.

En el chequeo del colimador multiláminas, por una parte verificamos coincidencias luz radiación, precisión en el posicionamiento de las láminas etc., y por otra parte se realizan controles en cada paciente de que los campos que se han exportado del planificador corresponden con la forma de los campos que se van a liberar en el acelerador. 
Además, con una periodicidad mensual, en nuestra institución liberamos un tratamiento complejo de IMRT en el acelerador y comprobamos por el procedimiento que señalamos mas adelante, las distribuciones de dosis se mantienen estables en el tiempo.

\section{Verificación experimental de los tratamientos}

De la dosis absoluta.

De las distribuciones de dosis.

El decidir seguir adelante o no con un tratamiento planificado está basado en la comprobación experimental del mismo. Este proceso comprendo dos pasos: la dosimetría absoluta en uno o más puntos de interés (normalmente con una cámara de ionización) y la comparación entre la distribución de dosis experimental con la calculada.

El primer paso será la elección del maniquí idóneo para la verificación (Fig. 1). Habrá que valorar, por una parte, su simplicidad de uso y por otra su adecuación a las patologías a las que estemos aplicando la IMRT.

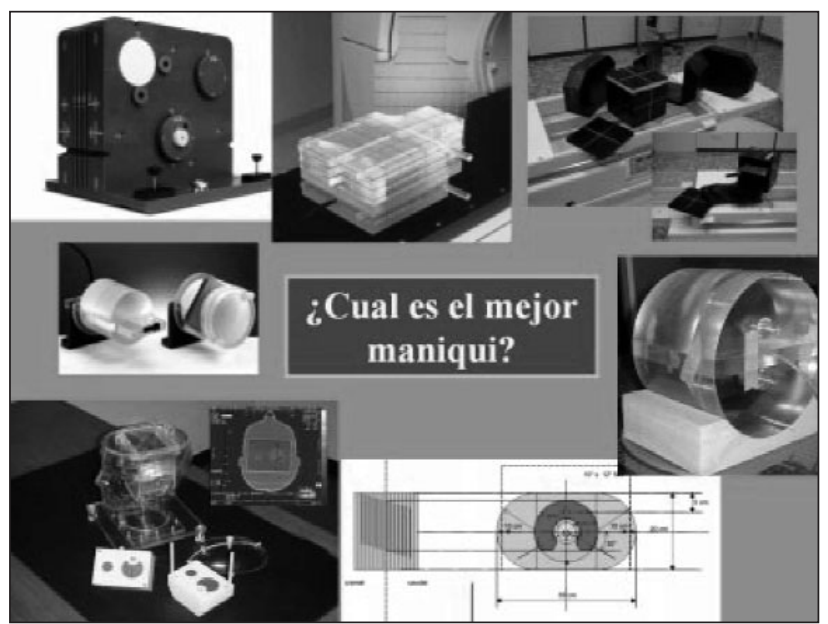

Fig. 1. Diferentes tipos de maniquíes para la verificación de la modulacion de intensidad.

En la Figura 2 se muestra el procedimiento general de verificación dosimétrica de un tratamiento de IMRT en nuestra institución.

La dosimetría fotográfica es el medio mas común y que se ha mostrado más fiable para este segundo propósito. Las características particulares de la dosimetría fotográfica y sus limitaciones inherentes requieren un estudio completo antes de empezar a utilizarla. El desarrollo de una herramienta de análisis adecuada para la dosimetría por película es necesario para la dosimetría por IMRT.

Para verificación de los tratamientos, en nuestra institución utilizamos las películas Kodac-EC y EDR-2. También hemos utilizado la película Kodak X-OMAT-V pero esta película se satura con niveles de radiación 50-60cGy mientras que la EC y EDR-2 llega hasta 400, con lo que cumple mejor los requerimientos en las sesiones de tratamiento. Necesitamos un escáner comercial de buena calidad que opere en transmisión. Además, necesitaremos una herramienta de análisis

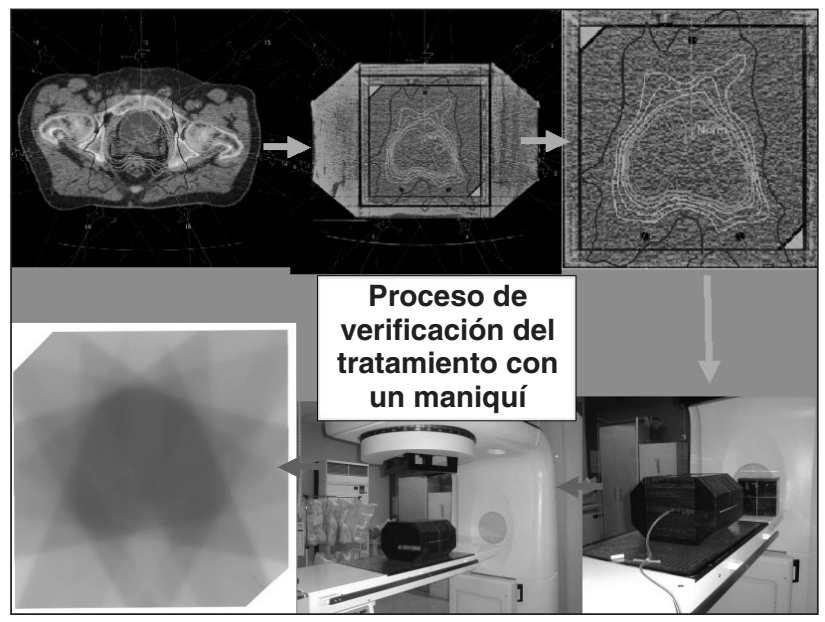

Fig. 2. El proceso de verificación de las distribuciones de dosis: primero, el plan de tratamiento aceptado se traslada a un maniquí en el cual se recalcula. Se envía este plan al acelerador con el cual se irradia el maniquí, con el mismo plan que vamos a tratar al paciente y por una parte se mide con una cámara de ionización la dosis absoluta y por la otra irradiamos el maniquí, en el cual hemos situado películas radiográficas para comparar distribuciones de dosis.

para validar los tratamientos. El parámetro más utilizado actualmente para validar las distribuciones de dosis es el factor gamma, el cual da más importancia en las zonas de bajo gradiente de dosis a la diferencia de dosis entre la medida y la calculada, y en las zonas de fuerte gradiente de dosis a la distancia entre la dosis calculada y la medida'.

\section{Bibliografía}

1. Daniel A Low et al. A tecnique for the quantitative evaluation of ose distributions. Medical Physics 1998, 25.

2. Basic applications of multileaf collimators: Report of The AAPM. Radiation Therapy Committee Task Group2001, no 50.

3. Guidance document on delivery, treatment planning, and clinical implementation of IMRT: Report of the IMRT subcommittee of the AAPM radiation therapy committee. 2003

4. Webb S. Intensity-Modulated Radiation Therapy. Institute of Physics publishing. Bristol and Philadelphia, 2001

5. Webb $S$. The physics of three dimensional radiation therapy. Institute of Physics publishing. Bristol and Philadelphia, 1993.

6. Quality Assurance in Radiotherapy Physics. Procedeedings of an American College of Medical Physics Symposium. May 1991.

7. The Modern Technology of Radiation Oncology. Editor Jacob Van Dick. Medical Physics Publishing. Madison, Wisconsin, 1999.

8. Sánchez-Doblado F, Arrans R, Leal A, Roselló J, and Carrasco E. Verification of IMRT, ISBN 84-95454-580, University of Seville, Spain 2001

9. Leal A, Sánchez-Doblado F, Arrans R, Roselló J, Carrasco E, Lagares Jl. Routine IMRT verification by means of an automatic MC simulation system. Int J Rad Oncol Biol Phys 2003; 56:58-68.

10. González A, Roselló J, Ruiz JC, Núñez L, Pérez J, Calatayud F y cols. Diseño de un maniquí para verificaciones dosimétricogeométricas de tratamientos con intensidad modulada. Física Médica 2001; 2(1). 